\title{
패션필름의 유형화에 따른 특성
}

\author{
권 지 안 · 임 은 혁 \\ 성균관대학교 의상학과 석사 - 성균관대학교 의상학과 부교수 ${ }^{+}$

\section{Characteristics and Categorization of Fashion Films}

\author{
Jeanne Kwon - Eun-Hyuk Yim \\ M.A., Dept. of Fashion Design, Sungkyunkwan University \\ Prof., Dept. of Fashion Design, Sungkyunkwan University \\ (received date: 2016. 3. 29, revised date: 2016. 5. 2, accepted date: 2016. 5. 16)
}

\begin{abstract}
Unlike the past, when fashion brands adopted unilateral communication with their consumers, the brands today have recognized the importance of bi-lateral communication. This has led to the companies producing fashion films as a means to elicit a consensus in opinion between the brands and the consumers. Such fashion films should be understood as films using fashion that transcends time, and also as a type of fashion media. This study, which is based upon the understanding that fashion films are a part of strategic marketing for enhancing the value of brands, used domestic and international literature in order to define fashion films, and establish a theoretical basis for these films. Corroborative study was also conducted for the purpose of practical categorization. This study aims to investigate the characteristics of fashion films, and to suggest a new approach to the study of fashion films. The study adopted the research methodology used in Dudley Andrew's film theory in order to create a theoretical frame that can be used to categorize fashion films. The theory is of significance because it is the basis for the category of motion picture fashion film and media technology fashion film. The study on the categorization and the characteristics of fashion films based upon 6 sub-categories shows a consistent trend of fashion films. From the results, it can be inferred that the films contribute, in part, to the enhancement of brand value. Fashion films have shown rapid growth with the mixture of other media, and with the introduction of cutting-edge technology. Fashion films can be used as new marketing methods for the fashion brands in this digital age.
\end{abstract}

Key words: fashion film(패션필름), fashion film platform(패션필름 플랫폼),

fashion image(패션이미지), media technology fashion film(미디어 테크놀로지 패션필름), motion picture fashion film(모션픽쳐 패션필름)

본 논문은 석사학위 청구논문 중 일부임.

Corresponding author: Eun-Hyuk Yim, e-mail: ehyim@skku.edu 


\section{I. 서론}

\section{1. 연구의 배경 및 목적}

현대사회에서는 물질적인 제품에 대한 정보보다 그 제품이 지닌 이미지(image, 심상(心象))가 중요해 지고 있다. 이는 특정 제품에 관한 정보보다 해당 제 품이나 브랜드가 지니고 있는 분위기나 환상과 같은 비물질적인 것에 대한 중요성이 높아지고 있기 때문 이다. 이러한 시대적 요구에 부응하기 위해 패션브랜 드는 옷과 더불어 브랜드 컨셉 또는 이미지를 통해 브랜드의 스토리텔링을 효과적으로 보여주기 위한 장치가 필요하게 되었고, 디지털 시대의 기술적 진보 와 더불어 패션필름이 그러한 역할을 수행하게 되었 다. 패션필름의 등장은 패션을 일련의 정지된 화면 또는 인쇄물의 시대에서 영상의 시대로 변화시키는 계기가 되었으며 미디어의 발달과 함께 다채로운 표 현을 할 수 있게 되었다. 이러한 패션필름은 패션브 랜드의 전략적인 홍보 방법으로 활용될 뿐만 아니라 소비자의 인식 구조 및 사회 전반에 영향을 미칠 수 있을 만큼 영향력이 확대되고 있다. 패션필름을 제대 로 이해하기 위해서는 패션필름에 대한 새로운 감식 안을 키워야 할 것이다(Jensen, 2005).

2000년대에 인터넷을 비롯한 뉴미디어의 확산과 더불어 패션브랜드는 2차원적인 소통방식을 뛰어넘 어 움직임이 있는 영상을 커뮤니케이션 방식에 도입 하였다. 패션필름은 소통을 기반으로 하는 패션미디 어로서 다양화된 현대 사회의 새로운 매체로 주목 받고 있다. 이에 본 연구에서는 미디어의 발달로 인 해 소비자의 능동적인 참여를 가능하게 하고 브랜드 의 아이덴티티 또는 이미지, 주제 등을 효과적으로 전달함으로써 패션브랜드와 소비자 사이의 소통을 이끌어내는 패션필름에 대해 분석해보고자 한다. 패 션필름에 관한 선행연구를 살펴본 결과 국내 선행연 구는 패션필름이 하나의 사례로서 활용되거나 $(\mathrm{Kim}$ 2014b; Jang \& Yang, 2010) 패션필름의 미적 특성 에 관한 가치 탐색 연구(Kim, 2013; Kim, 2013b)에 편향되어 있음을 알 수 있었다. 이 외에 문화와 예술 을 활용한 마케팅의 사례로서 패션필름을 연구(Kim, 2014a; Paik \& Bae, 2012)하거나 패션필름에 표현 된 메타리얼리티 개념의 특성을 도출한 연구(Kim \& $\mathrm{Ha}, 2015)$ 가 있었다.

한편 해외에서는 패션필름을 다각도에서 다루고 있는데, 스텔라 브루지(Stella Bruzzi, 1995)는 영화와 패션 사이의 관계가 상호보완적으로 발전할 것이라 예상하며 두 분야의 발전 방향에 관심을 두고 있으 며 나탈리 칸(Natalie Khan)은 패션필름을 하나의 장르로서 규정함으로써 심도 있게 연구하고 있다 (Stella, 2013). 이 밖에도 패션필름의 영향력에 대해 탐구한 연구(Bartlett, 2013) 및 패션필름을 역사적으 로 조망한 연구(Uhlirova, 2013), 패션의 역사와 더불 어 전달하고자 하는 의미와 정서를 교류할 수 있는 메커니즘으로서 패션과 영화를 이해한 연구(Andrea, 2013) 등 다양한 관점을 적용하여 연구를 진행하고 있음을 알 수 있었다. 이처럼 해외에서는 패션필름에 관하여 연구가 활발히 진행되고 있는 반면 국내 연 구 실정은 미흡한 편이다.

패션필름은 새로운 관점을 도입하여 기존에 존재 했던 것 또는 주목받지 못했던 대상을 중요하거나 창의적인 오브제로 인식할 수 있도록 하므로(Ryu, Han, Seo, Ahn, \& Lee, 2015) 브랜드의 마케팅 수 단으로 활용될 수 있다. 그 결과 럭셔리 브랜드를 비 롯하여 SPA 브랜드에 이르기까지 넓은 범위의 브랜 드 스펙트럼에서 활용되고 있다. 특히 20세기 후반에 들어서면서부터 수많은 패션필름이 제작되었고 그 제작 분량을 고려하면 패션필름의 역할과 영향력, 스 타일에 대해 짐작해볼 수 있다.

그러나 패션필름을 제대로 이해하기 위한 체계적 인 틀이 마련되어 있지 않아 패션필름이라고 하는 하나의 범주 안에서 이해할 수밖에 없었다. 최근에 등장한 패션필름은 다양한 장르와 테크닉이 접목되 어 명확하게 정의하기가 어려워지고 있다. 왜냐하면 사진과 영화, 과학기술 등 여러 분야에서 활용되는 형식과 기법이 패션필름에도 적용되고 있기 때문이 다. 이에 본 연구에서는 형식과 기법에 의거하여 패 션필름을 유형화하고 이를 통해 도출되는 패션필름 의 특성을 파악해보고자 한다. 이러한 연구 방법은 패션필름에 대한 새로운 접근 방법을 제시할 수 있 
을 것이다.

\section{2. 연구의 방법 및 범위}

본 연구에서는 패션필름을 유형화하기 위해 패션 필름의 개념과 특성에 관한 전반적인 연구 및 패션 필름의 유형화를 위한 표현 방법에 관한 이론을 바 탕으로 하는 문헌연구와 패션필름 사례를 분석하는 실증연구를 병행하고자 한다.

실증연구를 위해 사용된 자료는 각 패션 브랜드의 공식 홈페이지에 게재된 자료와 각 브랜드의 유튜브 (youtube)를 통해 수집하였다. 왜냐하면 유튜브는 브 랜드의 패션필름을 대중에게 전파하는데 효과적이며 브랜드와 소비자를 연결하는 경로가 될 수 있기 때문 이다. 이와 더불어 닉 나이트(Nick Knight)가 운영하 는 쇼스튜디오(SHOWstudio)는 패션필름의 아카이브 (archive)로서 초기 패션필름부터 현재까지의 패션필 름을 모두 볼 수 있으므로 수집 범위에 포함하였다 (Bartlett, 2014). 2000년에 쇼스튜디오가 등장한 이래 로 비슷한 성격을 가진 영상 전문 사이트가 생겨나고 있으며 이를 통해 패션필름의 폭넓은 자료 수집이 용 이해졌다. 이에 본 연구에서는 각 브랜드의 공식 홈 페이지 및〈Table 1〉의 다양한 패션필름의 인터넷 플 랫폼으로부터 포괄적으로 자료를 수집하였다.
패션필름 유형화의 기준은 더들리 앤드루(Dudley Andrew)의 영화 이론 연구 결과 중 일부를 참고하 였다. 그 이유는 영화와 유사한 형태를 띠는 패션필 름 유형화 작업을 위해 영화이론을 연구한 더들리 앤드루의 연구결과를 토대로 하는 것이 타당하다고 생각하였기 때문이다. 본 논문에서는 더들리 앤드루 가 정립한 소재(raw material), 수단과 기법(method \& techniques), 형식과 형태(forms \& shapes), 그리 고 목적과 가치(purpose \& value)에 따른 분류기준 (Kim, 2001) 중에서 형태와 기법을 적용하여 유형화 하였다.

소재를 패션필름 유형화의 기준으로 삼는다면 촬 영과 시공간의 활용, 음향, 영화 내부 장치들에 관한 내용 모두를 복합적으로 분석해야 한다. 하지만 패션 필름이 영화의 형태를 일정부분 따르고 있다고는 하 나 영화제작에 필요한 모든 소재를 담고 있다고 볼 수는 없기 때문에 다양한 요소를 복합적으로 분석해 야 하는 소재에 의한 분류는 지양하였다. 또한 브랜 드에서 제작한 일부 패션필름과 개인 제작자 자신만 의 독특한 감성을 근간으로 한 예술성이 돋보이는 패 션필름의 제작의도를 정확하게 파악하는 것은 무리가 있다. 이에 본 연구에서는 패션필름의 형태와 영상에 구현된 기법을 중심으로 유형화를 진행하였다.

분석 방법으로는 영화의 고유한 형태를 따르고 있

〈Table 1〉 Internet Platform of Fashion Film

\begin{tabular}{|c|c|c|c|c|}
\hline $\begin{array}{c}\text { Internet Platform of } \\
\text { Fashion Film }\end{array}$ & Homepage Address & $\begin{array}{c}\text { Number of } \\
\text { Fashion Films } \\
\text { Available }\end{array}$ & $\begin{array}{c}\text { Number of } \\
\text { Fashion Films } \\
\text { Observed }\end{array}$ & Selection Criteria \\
\hline SHOW studio & http://showstudio.com & 336 & 151 & \multirow{5}{*}{$\begin{array}{l}\text { fashion films with } \\
\text { traditional film form with } \\
\text { a clear message(fiction } \\
\text { fashion film, documentary } \\
\text { fashion film, animation } \\
\text { fashion film) } \\
\text { fashion films with } \\
\text { computer graphics and } \\
\text { cutting-edge } \\
\text { technique(motion graphic } \\
\text { fashion film, projection } \\
\text { mapping fashion film, } \\
\text { hologram fashion film) }\end{array}$} \\
\hline vimeo & https://vimeo.com & 7,473 & 1,085 & \\
\hline NOWNESS & https://www.nowness.com & 298 & 119 & \\
\hline $\mathrm{i}-\mathrm{D}$ & https://i-d.vice.com/en_gb & 100 & 31 & \\
\hline youtube & https://www.youtube.com/ & 6,088 & 1,831 & \\
\hline
\end{tabular}


는 패션필름 중에서 전달하고자 하는 메시지가 명확 하게 드러나는 사례를 중심으로 한 모션픽쳐 패션필 름과 컴퓨터 그래픽과 첨단기술을 융합한 기술적 측 면이 부각된 패션필름을 미디어 테크놀로지 패션필 름 유형으로 분류하였다. 모션픽쳐 패션필름은 영화 의 장르에 따라 픽션 패션필름과 다큐멘터리 패션필 름, 애니메이션 패션필름으로 세분화하였고, 미디어 테크놀로지 패션필름은 컴퓨터 그래픽 기술과 더불 어 영상 내 사용된 첨단기술에 따라 모션그래픽 패 션필름과 프로젝션맵핑 패션필름, 홀로그램 패션필름 으로 나누어 유형화하였다.

패션필름의 유형화를 위한 분석 자료로 활용한 사 례 범위는 2000년부터 2016년 사이에 제작된 패션필 름으로 제한하였다. 왜냐하면 패션필름이 적극적으로 제작되기 시작한 시기가 2000년 이후부터이며 현재 의 패션필름의 형태로 고착화된 시기라 할 수 있기 때문이다.

\section{II. 패션필름에 관한 고찰}

크리스토퍼 브루어드(Christopher Breward)는 잡 지나 신문, 웹 사이트, 광고, 음악 등과 같은 미디어 를 빠르게 받아들이고 이들과 결합하는 패션을 현대 사회의 문화를 이해하기 위한 핵심 요소로 보았다 (Sheridan, 2013). 이러한 융합의 일환으로 패션필름 이라는 뉴미디어가 등장하게 되면서 디지털 영상 이 미지인 패션필름의 영향력은 빠르게 확산되고 있다. 시간의 흐름에 따라 영상을 이미지화 할 수 있는 패 션필름이 새로운 시각적 패러다임으로서 자리매김하 고 있는 것이다. 패션필름이 기존의 미디어와 다른 점은 소비자 중심의 미디어라는 것이다. 이는 디지털 시대의 기술 향상과 더불어 소비자의 참여가 높아지 게 된 결과 브랜드와의 쌍방향 소통이 가능해진 덕 분에 발생한 현상이다. 이러한 상호작용성은 소통을 가능하게 하는 동시에 시간과 공간이 확장된다는 것 을 의미한다(Kim, 1999). 이러한 특성을 감안한다면 패션필름은 디지털 시대의 뉴미디어의 범주에 포함 될 수 있을 것이다.

공식 홈페이지 또는 각 브랜드에서 운영하는 유튜
브나 페이스북(facebook) 등의 경로를 통해 배포되는 패션필름은 $\mathrm{SNS}$ 사용자에 의해 영상이 편집되고 재 (再)유포되기도 한다. 이러한 개인의 참여는 소비자 와 브랜드 간의 물리적 거리감을 좁힐 수 있을 뿐만 아니라 인터넷을 기반으로 빠르게 확산되며 상당한 파급 효과를 지닌다(Lee, 2012). 이처럼 24시간 개방 되어 있는 디지털 아카이브(digital archive)는 사용 자 간의 소통을 확장시키고 그 결과 사용자 상호간 의 사고를 공유할 수 있는 공간으로서 역할하며 그 규모는 날로 증대되고 있다(Paik, 2010).

또한 패션필름은 특정한 시공간에서 이루어지는 일회성 이벤트라 할 수 있는 패션쇼에 영속성을 부 여하고, 패션쇼에 초대받은 소수의 사람만이 누릴 수 있었던 일종의 엘리트 문화를 대중화시킨 계기가 되 었다. 1910년 무빙 픽처 월드(Moving Picture World) 지에 한 필자가 주장한 것처럼 필름은 교양인과 교 양이 없다고 여겨지는 사람들 더 나아가 인종과 국 가의 장벽을 뛰어넘어 누구나 누릴 수 있고 공감할 수 있다고 하였다(Hansen, 1994). 이는 필름의 속성 을 지니고 있는 패션필름에서도 마찬가지이다. 패션 필름의 보편성은 필름이 지닌 민주화의 발현으로서 현대사회에 만연한 문화자본의 빈부격차를 줄이는 역할을 할 수 있을 것이다(Stam, 2012).

패션필름은 기존의 다른 미디어에서 체험할 수 없 었던 것을 체험하게 함으로써 정서적인 측면을 풍요 롭게 할 수 있다. 패션브랜드는 소비자와 능동적인 커뮤니케이션을 하는 방향으로 나아가기 때문에 패 션브랜드의 1차적 목적인 제품 홍보뿐만 아니라 라 이프스타일에도 영향을 미칠 수 있다. 그 결과 소비 자는 브랜드의 이미지와 자신을 동일시하려는 경향 을 나타내며 과시의 목적으로 소비하던 과거와 달리 현대에는 상징적 소비를 더욱 가치 있는 것으로 인 식하는 현상을 엿볼 수 있다(Do, 2014). 소비자는 사 람이 아닌 컴퓨터와 같은 제품이나 동물과도 동일시 하는 경향을 통해 자신의 욕구를 자극할 수 있다 (Kim \& Shim, 2009). 그 결과 패션필름은 과거와의 연계 속에서 변형되고 응용된 새로운 형태의 디지털 미디어라 할 수 있으며 영상의 이미지화와 브랜드 홍보, 상호작용성, 대중성, 개방성 등의 특성을 지닌 
홍보 수단으로서 이해할 수 있다.

이에 본 연구에서는 패션을 주제로 다루는 영상물 로서 패션필름을 정의하고자 하며 패션쇼 영상과 더 불어 제품 광고 영상, 단편 영화, 애니메이션 등이 포함될 수 있는 포괄적인 개념으로서 패션필름을 이 해하고자 한다. 더불어 패션브랜드 또는 패션브랜드 로부터 재정적 지원을 받아 제작된 패션필름 전반 및 패션쇼나 전시 및 일회성 이벤트를 영상으로 촬 영하여 재편집을 거쳐 하나의 영상으로 제작된 것도 넓은 범위에서의 패션필름으로 이해하고자 한다.

소비자와의 소통과 브랜드 스토리의 전달이 중요 해지면서 패션브랜드에서는 패션필름을 다양한 방식 으로 활용하고 있다. 최근에는 패션필름이 스토어와 모바일, 인터넷 광고 등의 미디어와 결합하여 시너지 효과(synergy effect)를 이끌어 내기도 한다. 이러한 방법은 기존 매체를 활용함으로써 각각의 매체가 가 지고 있는 영향력을 극대화시킴과 동시에 패션필름 의 특성인 공감각적인 경험을 통해 브랜드를 인지시 킴으로써 보는 이의 기억 속에 오랫동안 잔상을 남 길 수 있다. 그 중에서도 특정 공간에서 소비자와의 상호작용을 증대시키는 목적을 지니고 있는 패션 플 래그쉽 스토어와 패션 전시, 패션쇼 등이 최근 패션 필름의 플랫폼으로서 각광받고 있다. 왜냐하면 물리 적이고 상업적인 공간에서 이루어지는 소비자와의 소통은 소비자로 하여금 브랜드를 총체적을 체험할 수 있도록 하며 공간과 상품, 브랜드 아이덴티티, 소 비자를 하나로 연결할 수 있는 연결고리로서 역할하 기 때문이다. 이처럼 패션필름은 다양한 플랫폼을 기 반으로 하여 활용범위가 점차 증대될 것으로 보인다.

\section{III. 패션필름의 유형}

패션필름은 독립적인 장르로서 자신만의 영역을 구축하고 있으나 영화의 특성을 일정 부분 지니고 있기 때문에 본 연구에서는 패션필름의 사례를 살펴 보는 과정에서 영화의 분석 방법을 적용하고자 한다. 영화이론가 더들리 앤드루는 영화에 대한 도식적 이 해를 체계화하는 것을 목표로 소재, 수단과 기법, 형 식과 형태, 목적과 가치를 분류 기준으로 삼아 영화
를 분류하고자 하였다(Kim, 2001).

패션필름의 초기 제작자는 영화감독과 사진작가가 주를 이루었는데 영화감독은 영상의 형태적인 측면 을 기반으로 하는 형식 중심의 패션필름을 제작하였 고 사진작가는 영상 속에 구현된 표현기법과 같은 기술적 측면에 중점을 두어 패션필름을 제작하였다. 크리스티앙 메츠(Christian Metz)는 미래의 영화는 영화의 고유한 특성을 지니면서도 기법을 진일보시 키기 위한 도구로서 컴퓨터 기술을 적극 활용해야 할 필요가 있다고 하였다( $\mathrm{Lev}, 2004)$. 더불어 비서사 적 형태의 영상물이 다수 제작될 것이라고 말하면서 현실을 재현해내기 위한 기법이나 효과에 연연할 필 요가 없다고 했다. 2000년부터 2016년까지 발표된 다 수의 패션필름 사례를 살펴본 결과 크리스티앙 메츠 가 언급한 대로 패션필름도 영화의 형태를 고수하면 서도 다양한 컴퓨터 기술이 돋보이는 작품이 다수 제작된 것을 볼 수 있었다. 이에 본 논문에서는 더들 리 앤드루의 영화연구 방법의 기준이 되는 방식 중 형식과 기법을 원용하여 패션필름의 도식적 체계화 를 수행하고자 한다. 이에 본 연구에서는 패션필름을 형식적인 측면에 주안점을 둔 모션픽쳐 패션필름과 기술적인 측면에 바탕을 두고 있는 미디어 테크놀로 지 패션필름으로 나누고 이를 세분화하여 각각의 특 성에 대해 살펴보고자 한다.

\section{1. 모션픽쳐 패션필름(motion picture fashion} film)

패션필름은 그 명칭에서 알 수 있듯이 패션과 영 화의 합성어이다. 이는 패션필름이 일정 부분 영화의 형식을 차용하고 있음을 짐작할 수 있는 부분이기도 하다. 초기 패션필름의 제작자 중 영화감독이 큰 비 중을 차지했었기 때문에 패션필름이 영화의 형식을 띠는 것은 자연스러운 결과물로서 이해할 수 있을 것이다. 모션픽쳐 패션필름은 주로 영화감독에 의해 제작되어 영화의 형식을 따르고 있으며 등장인물과 대사, 음악, 배경, 미장센 등과 같은 구성에 초점을 맞추어 제작된다는 특성을 지닌다. 


\section{1) 픽션 패션필름(fiction fashion film)}

픽션 패션필름은 브랜드 광고를 위한 목적 외에 독자적인 내러티브 또는 메시지를 담고 있거나 전통 적인 영화의 형식을 차용한 패션필름으로 정의하고 자 한다. 픽션 패션필름은 고전 헐리우드 영화의 특 징이라 할 수 있는 기승전결의 구조를 가진 패션필 름뿐만 아니라 명확한 기승전결은 아니지만 전달하 고자 하는 메시지를 담고 있는 패션필름도 포함하고 자 한다. 또한 대부분의 픽션 패션필름은 영화감독 출신의 제작자에 의해 제작되는데 제작자의 성향에 따른 영화적 속성과 독자적인 내러티브를 담고 있는 사례들을 찾아볼 수 있다. 영화감독은 자신만의 독특 한 연출 기법을 패션필름에 반영함으로써 브랜드의 이미지와 자신의 특징을 자연스럽게 하나로 녹여내 기 때문에 마치 한 편의 영화를 보는 듯한 느낌을 받을 수 있다.

〈Fig. 1〉은 션 엘리스(Sean Ellis) 감독이 사랑이 라는 주제를 가지고 세 커플의 사랑 이야기를 옴니 버스 형식으로 구성하여 보여준 까르띠에(Cartier)의 패션필름이다. 해당 패션필름에는 출국하려는 여성의 여권을 숨겨두었다가 남성이 찾은 것처럼 여권과 함 께 까르띠에 반지를 주며 프로포즈하는 커플과, 로댕
(Rodin) 박물관에 있는 The Thinker의 조각품에 까 르띠에 반지를 숨겨두고 찾아올 수 있도록 이동경로 를 사진으로 찍어 보내주는 커플, 만원(滿員)인 엘레 베이터에 타고 있는 여성에게 자신의 마음을 전달하 기 위해 계단으로 따라 올라가며 엘레베이터 문이 열릴 때마다 까르띠에 반지와 함께 자신의 마음을 표현하는 커플이 등장한다. 이 때 까르띠에의 반지는 남자와 여자의 사랑을 확인할 수 있는 매개체로서 역할 하는 것을 알 수 있다. 이는 결혼을 약속한 남 녀 및 앞으로 결혼을 할 수 있는 불특정 다수의 남 녀에게 까르띠에 반지는 사랑을 약속하는 증표로서 역할 한다는 메시지를 전달할 수 있다.

미우미우(MiuMiu)의 Muta는 아르헨티나 출신의 여성 감독 루크레시아 마르텔(Lucrecia Martel)이 제 작한 패션필름이다. 그녀는 이해하기 쉽지 않은 형이 상학적인 예술영화를 주로 제작하는 감독으로서 이 러한 감독의 성향이 Muta에서도 나타나는 것을 볼 수 있다. 미우미우의 옷과 가방, 액세서리 등이 등장 하는 것을 제외한다면 영상의 분위기와 음향 효과 등의 전반적인 스타일은 마치 예술영화를 보는 듯한 느낌을 준다. 또한 일본 공포영화에서 유령의 모티프 및 영화 촬영 기법을 차용함으로써 공포스럽고 음산
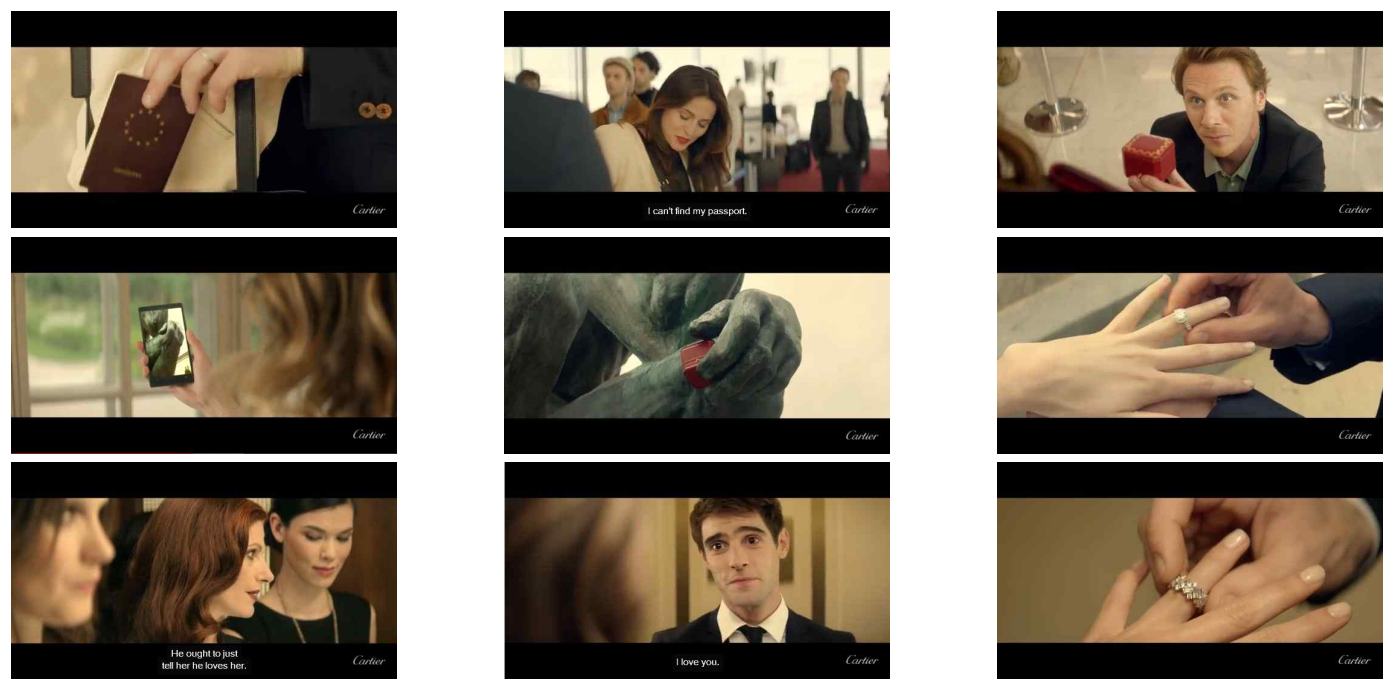

〈Fig. 1〉 The Proposal

(Cartier, 2015)

$-133-$ 


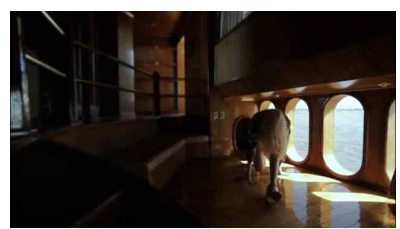

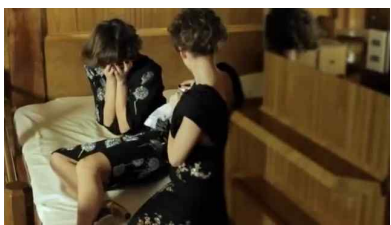

〈Fig. 2〉 Muta

(MiuMiu, 2011)

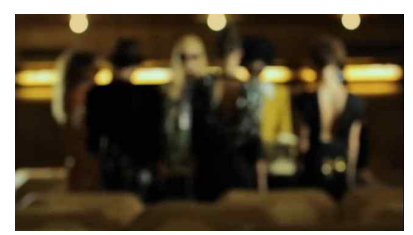

한 분위기를 고조시키고 있다(Stella, 2013). Muta의 이야기 전개 방식이 명확하지는 않지만 영상을 통해 전달하고자 하는 메시지가 있다는 것을 알 수 있는 데 Muta에 등장하는 수많은 여성 모델들의 얼굴이 의도적으로 보이지 않도록 연출한 점을 통해 메시지 를 유추해볼 수 있다. 〈Fig. 2〉에서 알 수 있듯이 영 상에 등장하는 모델들은 뒷모습 또는 아웃포커싱 (out-focusing) 되거나 고의적으로 얼굴을 가린 채 등 장한다. 이는 남성의 시선에서 보이는 여성의 모습에 대한 거부를 나타내며 전통적인 응시의 개념과 인식 에 대해 다시 한 번 생각해볼 수 있는 계기를 제안 하는 것으로 이해할 수 있다(Mijovic, 2013).

이 밖에도 2015년 발렌시아가(Balenciaga)의 $\mathrm{My}$ theresa는 친구들의 모임에 항상 늦게 나타나 핑계를 대는 여성의 모습을 담았다. 그 여성은 차 키를 찾기 위해 가방을 찾다가 가방 속에서 빛이 나며 새로운 세계가 있었다고 말한다. 그러한 여성의 말을 믿을 수 없는 친구들이 가방을 열어보고는 새로운 세계를 경험하게 된다. 이는 발렌시아가 가방은 지금껏 접하 지 못했던 새로운 느낌과 경험을 제공할 수 있다는 메시지를 전달한다. 또한 에르메네질도 제냐 $(\mathrm{Er}-$ menegildo Zegna)에서는 2014년 영화감독 박찬욱을 기용하여 패션필름을 제작하였다. 박찬욱 감독은 $\mathrm{A}$ Rose Reborn이라는 패션필름을 통해 새로운 세대가 문화와 지리적인 한계에 구애받지 않고 혁신적이고 유연한 태도를 가진 새로운 리더십을 지닌 세대로 변모하는 모습을 주인공이 정체불명의 사나이와 수 트를 바꿔입는 것을 통해 표현하였다(Hwang, 2014).

이처럼 픽션 패션필름은 영화의 형식을 기본틀로 삼고 있기 때문에 소비자는 영화를 볼 때처럼 내용 전개나 흐름에 집중하게 되고 영상이 담고 있는 이
야기나 메시지를 이해하기 위한 노력을 해야 한다. 또한 픽션 패션필름은 스토리나 대사, 음악, 미장센 등과 같은 요소들이 밀접하게 조합되어 있기 때문에 소비자가 등장하는 주인공이나 사물에 자기 자신을 투영시켜 감정이입을 할 수 있는 높은 몰입감을 줄 수 있다. 이런 특징을 통해 브랜드 체감 효과 역시 높일 수 있을 것이다.

\section{2) 다큐멘터리 패션필름(documentary fashion film)}

다큐멘터리 패션필름은 영화의 다큐멘터리 형식과 유사한 패션필름으로서 사실적인 묘사를 추구한다. 다큐멘터리 영화는 미리 정해진 시나리오나 사전 준 비 없이 즉석에서 연출하고 촬영할 수 있는 가능성 을 담고 있기 때문에(Jeon, 1994) 다큐멘터리 패션필 름도 개인의 일상생활이나 자연 경관을 보는 느낌이 들도록 최대한 담담하게 분위기를 이끌어가는 것이 특징이다. 다시 말해 다큐멘터리 패션필름은 영상과 스토리가 극적인 연출에 의해 조작된 느낌을 최소화 하여 실제를 있는 그대로 보여주려는 느낌의 패션필 름으로 정의하고자 한다.

폴 스미스(Paul Smith)는 제작자이자 감독인 세 바스찬 몬테즈 로셋(Sébastien Montaz-Rosset)과 암 벽을 등반하는 슬래크라이너(slackliner) 앙투안 모앙 빌(Antoine Moineville), 통크레드 멜레(Tancrède Melet)와 함께 프랑스 알프스(French Alps)에서 $2013 \mathrm{~A} / \mathrm{W}$ 언더웨어 패션필름을 촬영하였다. 두 명 의 슬래크라이너가 알프스산을 올라 두 개의 돌기둥 정상 사이에 줄을 매어 줄타기하는 모습 등 합성을 의심할 정도로 믿기 어려운 모습이 담겨있다. 이는 익스트림 스포츠 영상을 보는 듯한 착각이 들 정도 로 아찔한 느낌을 준다. 〈Fig. 3 〉의 폴 스미스의 패 

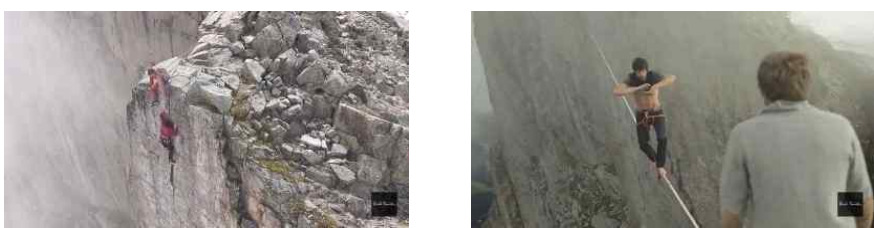

〈Fig. 3〉 Paul Smith Underwear A/W (Paul Smith, 2013)

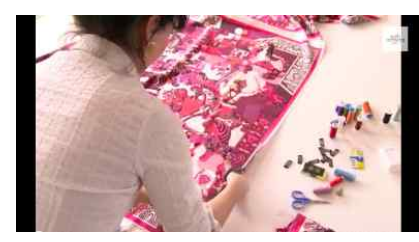

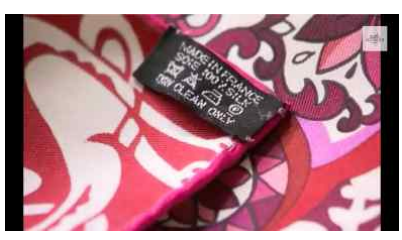

〈Fig. 4〉 Roulotter-Hand rolling (Hermès, 2011)

션필름에 등장하는 슬래크라이너들은 줄 하나에 자 신의 몸을 의지한 채 줄 위를 걷고 매달리고 옷을 벗는 등 줄 위에서 자유를 만끽하는 듯 보인다. 영상 을 보는 소비자는 마치 슬래크라이너들에 관한 휴먼 다큐멘터리를 보는 듯한 느낌을 받을 수 있는데 이 는 휴먼 다큐멘터리에 내재되어 있는 사실성과 진정 성을 접목시키고자 한 것이라고 이해할 수 있다.

다큐멘터리 패션필름에는 등장하는 사람의 독백으 로 진행되는 패션필름 못지않게 제품을 만드는 과정을 가감 없이 보여주는 메이킹 패션필름(making fashion film)의 사례도 높은 비중을 차지한다. 특히 메이킹 패션필름의 경우 브랜드의 오랜 전통과 역사를 지닌 브랜드에서 자신의 브랜드 헤리티지를 소비자에게 전달하기 위한 목적으로 사용된다. 〈Fig. 4〉의 에르 메스(Hermès) 패션필름에서는 브랜드의 시그니처 제 품이라 할 수 있는 스카프의 수작업 영상을 통해 장 인정신을 지닌 브랜드 이미지를 전달하고자 하였다.

2014년 제작된 루이비통(Louis Vuitton)의 패션필 름인 Desert Philosophies with Matthias Schoenaerts - On Travel and Discovery는 영화배우 마티아스 쇼 에나에츠(Matthias Schoenaerts) 가 혼자 여행하는 것 을 찍은 듯한 다큐멘터리 형태의 패션필름이다. 영상 에서 그는 마치 독백을 하듯 이야기하며 주변에 아 무도 없다는 듯 자연스럽게 행동한다. 또한 그를 찍
고 있는 카메라의 각도나 조명도 자연스러운 분위기 를 해칠 수 있는 과도한 설정을 피하고 있으며 등장 인물도 카메라를 직접적으로 응시하지 않고 있다. 이 를 통해 사실적인 다큐멘터리의 느낌을 극대화하고 자 한 것을 볼 수 있다.

다큐멘터리 패션필름은 인위적인 연출을 배제하고 시간의 흐름에 따라 자연스러운 영상미(映像美)를 추구하는 기록물의 성격을 띠며 특정 사건 또는 상 황을 사실적인 묘사를 통해 담아내는 영상이기 때문 에 맥락이 중요한 역할을 담당한다. 또한 다큐멘터리 는 자연이나 일상 또는 심도 있는 주제를 다룸으로 써 고유한 아우라가 생기게 된다. 다큐멘터리의 이러 한 분위기를 패션필름에 도입함으로써 다큐멘터리의 영상미와 느낌을 패션필름에 도입하고자 하는 의도 를 알 수 있다.

또한 다큐멘터리 패션필름에 해당하는 사례로 액 세서리 메이킹 영상이나 튜토리얼(tutorial) 영상이 많은 비중을 차지하고 있는 것을 볼 수 있었는데 이 런 현상은 브랜드의 매출과 연관지어 이해할 수 있 다. 컬렉션에 등장한 고가 제품의 판매 수익보다 향 수나 화장품, 가방과 같은 잡화에 의한 이익이 브랜 드 총 수익의 상당 부분을 차지하고 있는데, 이는 큰 금액을 지불하지 않고도 럭셔리 브랜드 제품을 구입 할 수 있다는 점이 소비자에게 매력적인 요소로 작 
용하기 때문이다. 그렇기 때문에 각 브랜드에서는 다 수가 구입 가능한 제품의 튜토리얼 영상이나 메이킹 영상을 제작함으로써 누구나 손쉽게 브랜드를 경험 하고 소유할 수 있도록 하는 것이다.

\section{3) 애니메이션 패션필름(animation fashion film)}

최근 럭셔리 브랜드의 패션 애니메이션은 브랜드 의 시즌 컬렉션 홍보와 더불어 브랜드의 이미지 및 정체성을 전달하는 수단으로 활용되고 있다. 애니메 이션은 영상 기술의 발달과 함께 발전해왔으며 단순 한 하나의 기술에서 멈추지 않고 영화사에 하나의 장르로서 자리매김하였다. 이러한 애니메이션은 패션 필름에서도 활발히 사용되고 있는데 애니메이션 패 션필름은 여타의 패션필름 유형과 달리 남녀노소 구 분 없이 다수의 사람들과 공유할 수 있고 소통할 수 있다는 특징이 있다.

루이비통은 일본의 아티스트 타카시 무라카미(Takashi Murakami)와의 협업 6주년을 기념하기 위해 2009년 〈Fig. 5〉의 Superflat First Love라는 애니메이션 패 션필름을 공개하였다. 영상은 판다가 여자 주인공을 집어 삼키면서 루이비통 세계로의 여행이 시작된다. 루이비통의 모노그램과 멀티 모노그램, 다미에 등으 로 구성된 다양한 패턴 속으로 빨려 들어가다가 루이 비통 3세대인 가스통-루이비통(Gaston- Louis
Vuitton)의 젊은 날의 모습과 여자 주인공이 만나게 된다. 그러나 곧 헤어지고 여자 주인공은 현실로 돌 아오게 되는데 자신이 보고 경험했던 루이비통의 세 계를 회상하는 것으로 영상은 끝을 맺는다.

루이비통의 애니메이션 패션필름은 형형색색의 로 고가 가득한 루이비통이라는 세계의 모험이 경쾌한 음악과 어우러지면서 밝고 활기찬 이미지를 브랜드 와 연계시키고자 했던 의도를 알 수 있다(Kim, 2014). 또한 젊은 층을 겨냥한 브랜드 이미지 쇄신을 위해 애니메이션 기술을 활용한 패션필름을 제작함으로써 당시 루이비통이 달성하고자 했던 브랜드 이미지 형 성과 더불어 매출 증가에도 도움을 주었다(Hong \& Kim, 2013; Seo \& Kim, 2014).

에르메스의 Super $\mathrm{H}$ 는 제목에서부터 슈퍼맨 또는 배트맨을 연상하게 되는데 영상을 보고 있노라면 자 연스럽게 영화와 오버랩(overlap)되는 현상을 경험할 수 있다. 영상 초반 자정의 시각 파리를 배경으로 에 펠탑에서 $\mathrm{H}$ 로고의 신호를 보내면 슈퍼맨과 배트맨 의 망토처럼 에르메스 스카프가 망토 형식으로 하늘 을 날아다닌다. 이 밖에 다른 영상은 나오지 않으며 〈Fig. 6〉의 마지막 사진에서처럼 Super H라는 로고 를 끝으로 영상을 마무리 짓는다. 에르메스는 실크하 우스(La Maison Des Carrés)의 스카프나 트윌리 등 을 직접적으로 등장시키거나 실크하우스를 주제로
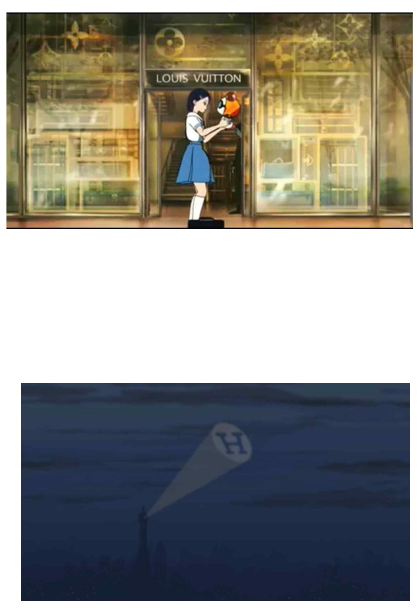

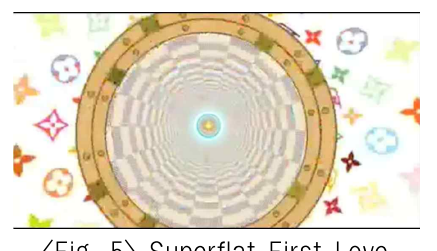

〈Fig. 5〉 Superflat First Love (Louis Vuitton, 2009)

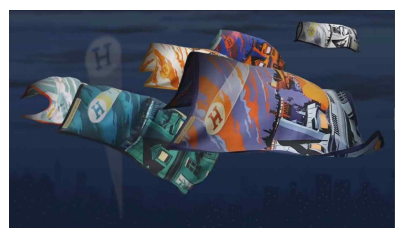

〈Fig. 6〉 Super $H$

(Hermès, 2014)

$-136-$
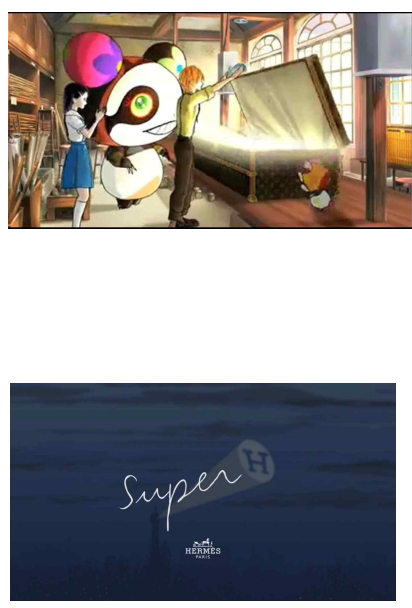
한 애니메이션 패션필름을 다수 제작하고 있는데, Super H를 비롯하여 2015년 Dans un jardin anglais 와 Hippopolis등이 있다.

영화에서 영웅을 부르거나 영웅의 등장을 알리는 신호로 여겨지는 어두운 밤하늘에 쏘는 빛과 영웅이 날아다니는 모습을 차용하여 에르메스의 패션필름에 서는 스카프가 그러한 영웅의 역할을 한다. 에르메스 는 대중적으로 유명한 영화의 익숙한 장면과 패션필 름을 애니메이션 기법으로 결합하여 보여줌으로써 친근감과 재미를 선사한다. 이는 고객층이 한정적인 럭셔리 브랜드의 한계를 극복하기 위한 방안이 될 수 있으며 브랜드를 대표하는 제품이자 비교적 대중 적인 스카프를 등장시킨 것은 많은 소비자의 구매를 유도하려는 의도로 파악할 수 있을 것이다.

돌체 앤 가바나(Dolce \& Gabbana)에서 2016년 제작한 Little Sicilian Man goes to Milan 애니메이 션에는 돌체 앤 가바나 캐릭터가 밀라노를 여행하는 모습이 담겨있다. 해당 패션필름은 15 초의 짧은 애니 메이션이지만 브랜드를 대표하는 캐릭터를 등장시켜 친숙한 느낌을 전달하고자 했을 뿐만 아니라 영상 마지막에 SNS 해시태그 장면을 등장시켜 소비자와 의 소통을 이끌어내고자 한 의도를 알 수 있다.

애니메이션 패션필름은 누구나 향유할 수 있는 오 락적 요소를 지닌 보편적 유형의 패션필름이라고 할 수 있다. 또한 최근 로봇이나 피규어 같은 장난감을 수집하고 소비하는 성인층이 확대됨에 따라 키덜트 (kidult)족의 취향이 긍정적인 방향으로 흘러가게 되 었고 이는 하나의 문화로서 자리매김하게 되었다. 브 랜드에서는 진지한 내용 대신 재미를 추구하는 키덜 트족의 취향처럼 애니메이션이라는 형식을 접목한 애니메이션 패션필름을 통해 천진난만한 성인층을 선점할 수 있을 것이며 이는 브랜드 인지도 제고 및 소비의 촉진으로 이어질 수 있을 것이다. 현대사회는 개인의 취향과 선택이 존중받는 사회이며 물질적 가 치보다 남과 다른 취향이 더욱 중요한 가치로 작용 하는 시대로 변모하고 있다(Shin, 2015). 이처럼 다 양한 취향이 존중되는 사회 분위기 속에서 애니메이 션 패션필름이 차지하는 위상이 상승하는 현상은 이 러한 맥락에서 이해할 수 있을 것이다.
모션픽쳐 패션필름은 영화의 구성적인 측면을 취 하고 있기 때문에 보는 사람으로 하여금 영상의 내 용에 상당한 집중력을 발휘할 수 있도록 한다. 소비 자가 단순한 구매자의 단계에서 머무르지 않고 영화 관에서 패션필름을 감상하는 관람객의 입장으로까지 확장되어 그 결과 그들의 감성을 자극함과 동시에 브랜드에 대한 동경심을 고취시킬 수 있다. 동시에 영상에 등장하는 주인공이나 사물에 자신을 투영하 여 감정이입을 극대화할 수 있다. 또한 모션픽쳐 패 션필름에 등장하는 제품은 해당 영상의 내러티브나 메시지보다 두드러지게 표현되는 것은 아니지만 스 토리의 전개상 비중 있는 역할을 담당함으로써 메시 지를 효과적으로 전달하고자 하는 것을 알 수 있다.

\section{2. 미디어 테크놀로지 패션필름(media technology fashion film)}

패션필름은 영상의 이미지화를 통해 커뮤니케이션 을 이끌어내는 미디어의 속성을 지니고 있으므로 넓 은 범주에서 살펴볼 때 미디어의 일종이라 할 수 있 을 것이다. 최근 미디어의 발전 방향은 디지털 기술 을 접목한 형태로 변모하고 있으며(Lee, 2006) 패션 필름도 이러한 경향을 적극적으로 수용하여 디지털 컨셉을 접목한 테크놀로지 중심의 패션필름을 제작 하고 있다. 이에 본 연구에서는 다양한 표현방식을 구현하기 위해 테크놀로지를 접목한 기술적 요소가 두드러지게 표현된 패션필름을 미디어 테크놀로지 패션필름으로 규정하고 그 중에 빈번하게 사용된 기 법 중심으로 유형화하여 각각의 특성을 살펴보고자 한다. 또한 미디어 테크놀로지는 디자인학을 비롯한 영상학, 인문학 등의 다양한 분야의 선행연구에서 (Yoon, Lee, \& Lee, 2003; Paik, 2011; Shin, 2004) 폭넓게 사용되고 있으므로 본 연구에서도 미디어 테 크놀로지라는 용어를 차용하고자 한다.

\section{1) 모션그래픽 패션필름(motion graphic fashion film)}

모션그래픽 패션필름을 살펴보기 전에 모션그래픽 에 대한 정의와 구성 요소에 대해 살펴볼 필요가 있 
다. 그러나 모션그래픽의 정의와 구성요소에 관한 일 관된 정의가 구축되어있지 않고 여러 학자가 다양한 분류 기준을 적용하고 있는 실정이다. 이에 본 연구 에서는 모션그래픽에 관한 선행연구를 바탕으로 모션 그래픽 패션필름의 구성요소로서 공통적으로 언급되 는 요소 및 모션그래픽 패션필름의 사례에서 보이는 특징을 바탕으로 모션그래픽을 재정의하고자 한다.

$\operatorname{Jang}$ (2006)에 따르면 모션그래픽은 공간(layer) 과 타이포그래피, 시간, 움직임, 사운드로 구성된다고 하 였으며, Cho(2009)는 시간과 움직임, 그래픽, 사운드 를 기준으로 삼았으며, $\mathrm{Hwa}(2013)$ 는 이미지, 움직임, 타이포그래피 세 가지의 시각적 요소로 나누어 살펴 보았다. 선행연구를 바탕으로 본 연구에서는 이미지 와 텍스트, 그래픽이 더해진 하나의 공간에 시간이라 는 요소를 결합하여 움직임의 변화를 통해 이야기하 는 형식을 지닌 것으로서 모션그래픽을 정의하고자 하며 이러한 특징이 반영된 패션필름을 모션그래픽 패션필름으로 분류하고자 한다.

〈Fig. 7〉의 가레스 퓨(Gareth Pugh) 패션필름은 전형적인 모션그래픽 패션필름의 사례라고 할 수 있 다. 그의 패션필름은 특정한 스토리를 담고 있지 않 으며 서로 인과관계가 명확하지 않은 쇼트들의 집합 체라 할 수 있다. 하지만 그의 영상은 가레스 퓨라는 브랜드의 이미지를 모션그래픽 패션필름을 통해 전
달하고 있다. 흑백의 대조적인 사용 및 음침하고 기 괴한 배경음과 아방가르드한 모델의 몸짓 등의 공포 스러운 분위기나(Kim, 2013) 데칼코마니(decalcomanie) 같은 좌우대칭이나 역동적인 모델의 움직임 을 통해 브랜드 고유의 아방가르드한 분위기를 짐작 할 수 있다. 또한 복식의 다양한 모습을 보여줌으로 써 복식 자체에 집중할 수 있도록 한다.

가레스 퓨의 패션필름에서 나타나는 특징을 담고 있는 패션필름으로 2014년 보테가 베네타(Bottega Veneta)에서 제작한 The Women's Intrecciato Nappa Slip-On Sneaker를 들 수 있다. 보테가 베네타의 영 상도 흑백의 대조를 바탕으로 좌우대칭 및 반복적인 움직임을 통해 모션그래픽의 특성을 나타내고 있다. 더불어 2016년 루이비통의 The Twist from Louis Vuitton featuring Alicia Vikander도 모션그래픽의 양상을 띠고 있다. 루이비통도 $2013 \mathrm{~F} / \mathrm{W}$ 액세서리 홍보를 위한 패션필름을 모션그래픽 기술을 기반으 로 제작하였다. 〈Fig. 8〉의 사진에서처럼 루이비통은 이미지의 변형과 그래픽을 콜라주하는 기법을 통해 재조합하고 좌우대칭적인 표현 같은 모션그래픽의 시각적 요소들을 바탕으로 구성하였다. 또한 화면을 확대 또는 축소하거나 채도의 변형, 텍스트 변형 등 의 기법을 바탕으로 깜박거리는 움직임을 통해 공간 의 유동성을 강조한 것을 알 수 있다(Yoo, 2004).
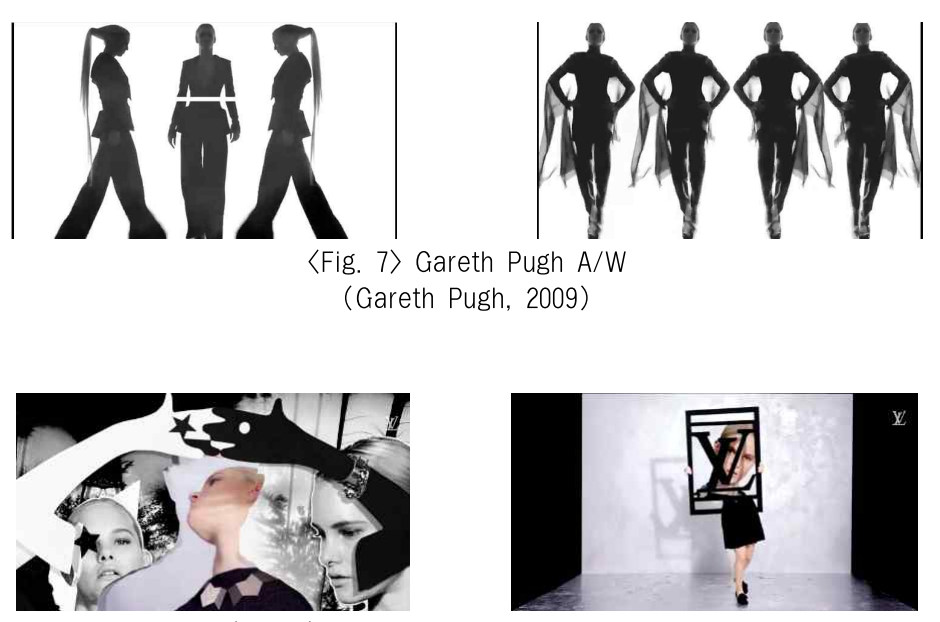

〈Fig. 8>Accessories with Quentin Jones

(Louis Vuitton, 2013) 
모션그래픽 패션필름의 경우 컴퓨터 그래픽과 같 은 다양한 표현 방식을 통해 영상 내 시각적인 볼거 리의 제공이 용이하고 브랜드에 첨단 이미지를 덧입 힐 수 있으므로 시대를 선도하는 브랜드 이미지를 얻을 수 있다. 또한 영상을 보는 주체에 의해 조작이 가능한데 영상의 재생과 정지, 장면이동을 통해 자신 이 원하는 프레임으로 즉각적인 이동이 가능하며 특 정 내러티브가 존재하지 않기 때문에 영상을 처음부 터 끝까지 이어서 보지 않아도 영상의 흐름에 큰 방 해요소가 되지 않는다.

\section{2) 프로젝션맵핑 패션필름(projection mapping fashion film)}

프로젝션맵핑(projection mapping)이란 빛을 비추 다라는 뜻의 프로젝션과 빛의 반사나 굴절에 의해 상 이 맺힌다는 의미의 맵핑의 합성어이다(Park, Kim, \& Jung, 2013). 이는 물리적인 형태를 가지는 오브 제에 빛을 투영시켜 본래의 모습과 다른 형태의 이 미지를 생성하는 것을 의미하는데, 특정 공간이나 오 브제에 영상을 맵핑하여 그 안에서 시각적인 착시나 환상적인 이미지를 형상화하는 기법이라고 할 수 있 다. 프로젝션맵핑 기술이 적용되는 오브제가 평면적 인 스크린일 경우보다 입체적인 건물이나 조형이 스 크린으로 사용될 경우 새로운 차원의 이미지가 창출
될 수 있다(Lee, 2013). 이처럼 프로젝션맵핑은 현실 을 기반으로 구현되기 때문에 보는 이로 하여금 프 로젝션맵핑이 활용된 패션필름을 거부감 없이 받아 들일 수 있도록 하며 다양한 감각의 활용을 통해 정 보를 습득하고 경험할 수 있기 때문에 체험적 성향 이 짙다(Lee \& Kwon, 2015).

랄프 로렌(Ralph Lauren)은 디지털 혁신을 맞이 하여 여성 플래그쉽 스토어 건물의 외벽에 빔을 쏘 아〈Fig. 9〉과 같은 프로젝션맵핑 패션필름을 제작하 였다. 랄프 로렌은 현실감을 극대화하기 위해 컴퓨터 그래픽에 사실감을 추가하는 렌더링 작업을 병행하 였으며 3차원의 공간에 물체와 일련의 이미지를 절 묘하게 결합하여 오감(五感)을 만족시킬 수 있는 패 션필름을 제작하고자 하였다. 그 결과 랄프 로렌의 패션필름은 예술과 패션, 기술 사이의 융합을 이끌어 냈다고 볼 수 있다. 물리적 장소와 결합한 랄프 로렌 의 프로젝션맵핑 패션필름은 특정 장소가 지니고 있 는 고유의 이미지나 기억 등을 브랜드에 맞게 재매 개화하여 소비자에게 새로운 의미를 전달할 수 있다. 또한 영상이 끝난 뒤 랄프 로렌의 향수를 공중에 분 사하여 오감을 통해 브랜드를 체험할 수 있도록 하 였다.

나이키(Nike)는 2011년 Melo M8 모델을 소개하 기 위한 방법으로 $4 \mathrm{D}$ 워터 프로젝션을 사용하였는데
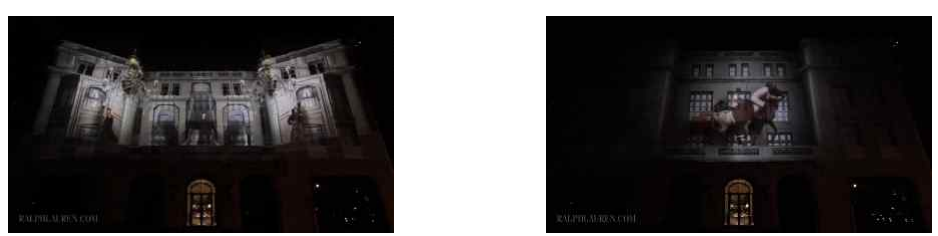

〈Fig. 9〉 The Official Ralph Lauren 4D Experience - New York (Ralph Lauren, 2010)
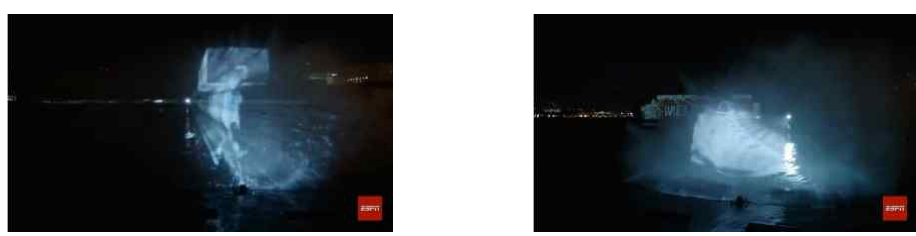

〈Fig. 10〉 Jordan Melo M8 Water Projection

(Nike, 2011) 
이는 물 미립자를 공중에 분사하여 수증막을 형성한 뒤 레이저 광선을 쏘아 영상을 투영시키는 방법이다. 〈Fig. 10〉의 나이키 패션필름에서는 실제 헬기에서 사람이 물속으로 뛰어든 후 그를 워터 프로젝션으로 구현하여 다시 수면 위로 등장시킨다. 프로젝션맵핑 기술로 구현된 모델은 나이키의 M8을 신고 실제 농 구 코트에서 경기를 하는 것처럼 수면 위를 가벼운 몸동작으로 뛰어다니며 덩크슛을 한다. 이를 통해 $\mathrm{M} 8$ 의 가벼운 착화감 등 기능적인 측면을 효과적으 로 부각시키고 있다.

첨단기술과의 융합이 잦은 랄프 로렌(Ralph Lauren) 은 2014년 워터 프로젝션 기술을 접목한 패션필름을 발표하였다. 나이키의 프로젝션맵핑 패션필름과 동일 한 방법으로 공중에 물 미립자를 분사하여 60 피트의 거대한 벽을 만들었으며 워터 프로젝션을 기반으로 맵핑 및 홀로그램 등 다양한 기술을 접목하여 패션 쇼를 선보였다.

프로젝션맵핑 패션필름처럼 건물이나 조형물을 스 크린으로 사용할 경우 소비자의 경험의 폭을 확장시 킬 수 있기 때문에 현존하는 오브제를 바탕으로 특 정 지역 및 시간대에 이벤트성으로 제작되는 경우가 많다. 이벤트가 실행되고 있는 과정을 촬영한 뒤 영 상의 재편집 과정을 거쳐 패션필름으로 제작하여 전 세계에 배포하는 방식을 취하고 있는 것을 알 수 있 었다. 또한 프로젝션맵핑 패션필름은 실제와 가상의 경계를 희미하게 함으로써 공간에 대한 재해석을 유 도하며(Lee, 2008) 다른 유형의 패션필름과 달리 체 험적인 측면이 부각되는 패션필름이라고 할 수 있다.

\section{3) 홀로그램 패션필름(hologram fashionf film)}

홀로그램(hologram)이란 홀로그래피(holography)
기술을 이용하여 입체 정보를 재생하는 것을 의미하 는데 이러한 홀로그램 기술을 활용할 경우 이미지를 3 차원 영상으로 구현할 수 있게 되어 눈앞에 없는 대상을 360도로 재현할 수 있다(Kim, Shin, \& Kim, 2014). 다시 말해 빛의 반사를 통해 특정 사물을 인 지할 수 있도록 하는데 특정 사물이 지닌 동일한 성 질의 빛을 홀로그램에서 발생시킬 수 있기 때문에 존재하지 않는 물체의 3 차원 입체가 눈에 보이게 되 는 것이다(Kwon, 2011). 패션필름에서 주로 사용되 는 홀로그램 기술은 플로팅 홀로그램 (floating hologram) 기술로 유사 홀로그램 기술로서 분류될 수 있 으나(Cheon, 2015) 본 연구에서는 이러한 플로팅 홀 로그램 기술이 사용된 패션필름도 홀로그램 패션필 름의 한 사례로서 살펴보고자 한다.

2006년 알렉산더 맥퀸(Alexander McQueen)은 패 션쇼에 홀로그램 기술을 접목하여 가상의 이미지와 현실을 혼합하였는데 이는 실재와 비실재의 간극을 불명확하게 하였다. 패션쇼가 끝난 후 삼각뿔 형태의 파사드(facade, façade)에 홀로그램이 투사되면서 케 이트 모스(Kate Moss)의 모습이 등장하였다. 〈Fig. 11) 속 케이트 모스는 어딘가 모르게 여린 여성의 모습으로 등장하였는데 그녀의 움직임은 환각상태에 서 영혼을 만나는 1860년대 Pepper's Ghost에서 영감 을 받았으며 이를 효과적으로 표현하기 위해 홀로그 램 기술이 사용되었다(Jung \& Kim, 2013). 3차원의 입체 형태로 그녀를 재현하여 마치 눈앞에서 직접 보는 것 같은 착시현상을 일으키고자 하였다.

알렉산더 맥퀸에 사용된 홀로그램 기술은 플로팅 홀로그램 기술과 유사하다고 할 수 있다. 무대 위에 설치된 프로젝터에서 바닥에 있는 스크린으로 미리 녹화해 둔 영상을 비추면 바닥의 영상이 무대 위에
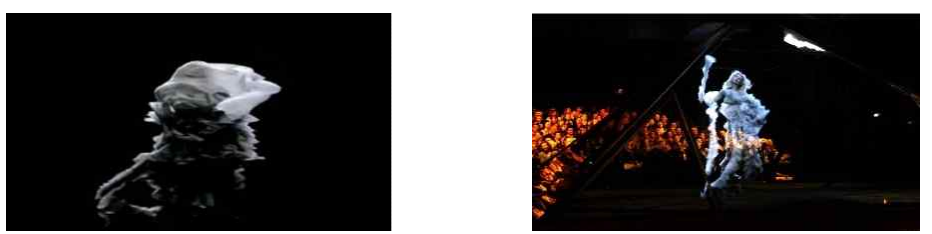

〈Fig. 11〉 Alexander McQueen F/W

(Alexander McQueen, 2006) 

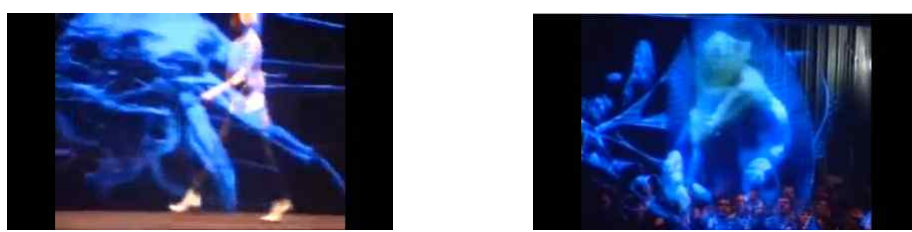

〈Fig. 12〉 Liquid Space Holographic Fashion Show (Diesel, 2007)

설치된 피라미드 모양의 파사드에 반사되어 관객에 게 보이게 되는 것이다. 이 때 관객은 프로젝터나 무 대 바닥에 있는 스크린은 보지 못하고 스크린에 반 사된 영상을 보고 허공에 영상이 등장한 것 같은 착 각을 하게 되는 것이다.

피티 워모(Pitti Uomo)에서 열린 디젤(Diesel)의 $2008 \mathrm{~S} / \mathrm{S}$ 프리뷰 컬렉션(preview collection)은 신비
로운 은하 세계를 주제로 패션쇼가 진행되었다. 홀로 그램이라는 기술을 부수적으로 활용하거나 온전히 홀로그램만으로 구성된 패션필름은 있었으나 홀로그 래픽을 통해 만들어 낸 가상의 물체와 실제 모델을 동시에 등장시켜 하나로 융합한 것은 디젤의 패션필 름이 처음이라 할 수 있다. 디젤은 액체 공간(Liquid Space)이라는 테마를 가지고 현실과 가상의 경계가

〈Table 2〉 Characteristics of Fashion Film

\begin{tabular}{|c|c|c|c|}
\hline \multicolumn{2}{|c|}{$\begin{array}{c}\text { Categorization of Fashion } \\
\text { Film } \\
\end{array}$} & \multirow[b]{2}{*}{$\begin{array}{l}\text { Individual Characteristics } \\
\text { consumers concentrating on the narrative of } \\
\text { fashion film thanks to the adoption of film } \\
\text { format } \\
\text { consumers in empathy with the characters } \\
\text { and objects in the film } \\
\text { all the audio-visual elements such as narrative } \\
\text { connected with brands }\end{array}$} & \multirow{4}{*}{$\begin{array}{l}\text { Characteristics in Common } \\
\\
\text { consumers can concentrate much } \\
\text { on the contents of the film like } \\
\text { spectators } \\
\text { empathy can be maximized } \\
\text { through projecting him(her) self } \\
\text { into the characters or objects } \\
\text { products appearing in the film } \\
\text { function as the tool for an } \\
\text { effective transmission of narrative } \\
\text { and message }\end{array}$} \\
\hline \multirow{3}{*}{$\begin{array}{c}\text { motion } \\
\text { picture } \\
\text { fashion film }\end{array}$} & $\begin{array}{c}\text { fiction } \\
\text { fashion film }\end{array}$ & & \\
\hline & $\begin{array}{l}\text { documentary } \\
\text { fashion film }\end{array}$ & $\begin{array}{l}\text { excluding any artificial production } \\
\text { serious atmosphere of documentary film inheres } \\
\text { stimulates consumers desire to possess with } \\
\text { the images showing generality }\end{array}$ & \\
\hline & $\begin{array}{l}\text { animation } \\
\text { fashion film }\end{array}$ & $\begin{array}{l}\text { inheres generality anyone can enjoy } \\
\text { reflects various tastes of individuals of modern } \\
\text { society }\end{array}$ & \\
\hline \multirow{3}{*}{$\begin{array}{c}\text { media } \\
\text { technology } \\
\text { fashion film }\end{array}$} & $\begin{array}{c}\text { motion } \\
\text { graphic } \\
\text { fashion film }\end{array}$ & $\begin{array}{l}\text { easily provides visual image } \\
\text { creation of pioneering brand image likely } \\
\text { continuity of contents unavailable }\end{array}$ & \multirow{3}{*}{$\begin{array}{l}\text { creation of epoch-making beauty } \\
\text { of image based on technology } \\
\text { mandatory adoption of } \\
\text { cutting-edge technology and } \\
\text { connection with industry } \\
\text { simultaneous usage of more than } \\
\text { two technologies }\end{array}$} \\
\hline & $\begin{array}{l}\text { projection } \\
\text { mapping } \\
\text { fashion film }\end{array}$ & $\begin{array}{l}\text { experiencing 3D spatial extension } \\
\text { event-like characteristics } \\
\text { emphasizes consumers' experience in } \\
\text { Augmented Reality }\end{array}$ & \\
\hline & $\begin{array}{c}\text { hologram } \\
\text { fashion film }\end{array}$ & $\begin{array}{l}\text { realistic 3D stereoscopic image available } \\
\text { suitable for the projection of the unlived world } \\
\text { and brand vision }\end{array}$ & \\
\hline
\end{tabular}


모호한 공간을 형성하기 위해 무대 위에 설치한 투 명막에 빛을 반사시켜 보여주는 홀로그램 기술을 활 용하였다. 〈Fig. 12〉와 같이 디젤의 패션필름을 살펴 보면 실제 모델이 캣워크를 걷는 동안 거대한 기계 적 두족류(頭足類) 동물과 은하계 파편, 미래의 생물 발광 세계가 함께 제시된 것을 볼 수 있다. 이처럼 홀로그램 기술을 활용한 패션필름은 보는 사람에게 현실감 있는 영상을 제공할 수 있기 때문에 관객에 게 시각적 환상을 제공할 수 있다.

버버리(Burberry)는 2011년 베이징 플래그쉽 스토 어 오픈을 기념하기 위해 전 세계 150 개국에서 동시 에 컬렉션을 볼 수 있도록 컬렉션 영상을 인터넷으 로 생중계하였다. 해당영상에는 홀로그램 기술을 바 탕으로 한 기술친화적인 이미지와 브랜드의 전통적 인 가치를 조화롭게 접목시킨 것을 엿볼 수 있다.

홀로그램을 활용한 패션필름은 다른 미디어 테크 놀로지 패션필름에 활용된 기술 중에서 3 차원의 입 체적인 영상을 현실감 있게 보여줄 수 있는 이상적 인 패션필름이라고 할 수 있다(Kwon, 2011). 그렇기 때문에 홀로그램과 같은 특수 기술이 반영된 패션필 름은 소비자에게 또 다른 세계에 대한 경험을 제공 할 수 있으며(Lee, 2008) 미래 또는 상상 속의 세계 를 구현하여 브랜드의 새로운 비전을 제시하기에 최 적화된 수단이라고 할 수 있다.

이처럼 미디어 테크놀로지 패션필름은 $3 \mathrm{D}$ 스캐닝 (3D scanning), 모션 캡쳐(motion capture) 등과 같 은 첨단기술을 접목시킨 것뿐만 아니라 두 가지 이 상의 기술이 함께 쓰여 새로운 영상미를 창안하는 것을 볼 수 있다. 이는 새로운 것을 추구하고 변화를 빠르게 수용하는 경향이 있는 패션의 특성이 미디어 테크놀로지 패션필름이라는 결과물을 도출한 것으로 이해할 수 있다. 이처럼 패션필름과 기술적 진보는 상생하는 관계에 있으며 기술적 발전은 패션필름의 심미적인 측면에 상당 부분 영향을 미치고 있다. 왜 냐하면 패션필름 내의 다양하고 새로운 표현을 위해 서는 필연적으로 새로운 기술 또는 산업과의 연계를 통해 가능하기 때문이다(No, 2014). 이러한 특징을 바탕으로 앞으로 더 많은 패션브랜드에서 테크놀로 지를 접목한 패션필름을 제작할 것이라 예상된다.

\section{$\mathrm{IV}$. 요약 및 결론}

본 연구는 브랜드와 소비자 사이의 교감을 이끌어 낼 수 있는 커뮤니케이션 도구로서 패션필름을 이해 하고 패션필름이 하나의 독자적인 분야로 인식되기 시작한 2000년 이후부터 제작된 패션필름의 사례를 바탕으로 패션필름을 유형화하였다.

그 결과 영화의 형식을 따르면서 전달하고자 하는 메시지나 독자적인 내러티브를 지니고 있는 모션픽 쳐 패션필름과 패션필름에 기술을 접목하여 스토리 의 연속성보다 시각적 유희가 두드러지는 미디어 테 크놀로지 패션필름으로 나눌 수 있었다.

모션픽쳐 패션필름은 영화의 형식적인 측면을 차 용하고 있으며 해당 패션필름만의 내러티브나 메시 지 등을 내포하고 있는 유형으로 픽션 패션필름과 다큐멘터리 패션필름, 애니메이션 패션필름으로 세분 화할 수 있는데, 첫째, 픽션 패션필름은 고전 헐리우 드 영화처럼 기승전결에 따라 내용이 전개되거나 전 달하고자 하는 메시지가 명확하다. 또한 패션필름의 스토리에 감정을 몰입할 수 있도록 하여 마치 한 편 의 영화를 감상하는 관람객이 된 듯한 느낌을 줄 수 있다. 둘째, 다큐멘터리 패션필름은 제작과정 상의 과도한 연출을 배제함으로써 자연스러운 영상미를 추구한 패션필름이라고 할 수 있다. 셋째, 애니메이 션 패션필름은 나이와 성별에 상관없이 누구나 즐길 수 있는 패션필름 유형으로서 보편적인 접근이 가능 하다. 이처럼 모션픽쳐 패션필름은 영상 속 내러티브 를 비롯하여 모든 시청각적인 요소가 브랜드와 직결 되어 있으며 이는 소비자의 소유욕을 자극할 수 있 다. 모션픽쳐 패션필름의 공통적인 특성은 영상의 스 토리나 메시지에 집중할 수 있는 구성력이 돋보인다 는 점이다.

미디어 테크놀로지 패션필름은 첨단기술을 패션필 름에 접목하여 시각적 유희를 전달하고자 하는 패션 필름으로서 모션그래픽 패션필름과 프로젝션맵핑 패 션필름, 홀로그램 패션필름으로 나누어 살펴보았다. 첫째, 모션그래픽 패션필름은 화려한 컴퓨터 그래픽 기술을 활용하여 시각적인 볼거리가 다양하며 소비 자에 의한 영상 조작이 영상의 흐름에 커다란 방해 
요소가 되지 않는다. 둘째, 프로젝션맵핑 패션필름은 실질적으로 존재하는 건물이나 사물을 바탕으로 제 작되기 때문에 체험적인 측면이 부각되며 가상과 현 실의 모호한 경계를 넘나드는 공간에 대한 확장적인 경험을 할 수 있다. 셋째, 홀로그램 패션필름은 눈앞 에 존재하지 않는 사물이나 인물을 입체영상으로 구 현함으로써 생동감을 증폭시킬 수 있기에 브랜드의 비전과 같은 무형의 환상을 현실감 있게 제시할 수 있다는 특성을 가지고 있다. 이처럼 미디어 테크놀로 지 패션필름은 다양한 기술과의 접목을 통해 다채로 운 영상미를 표현할 수 있다.

2005년 유튜브의 등장 이후 패션필름은 빠른 성장 세를 이어오고 있는데 그 이유는 유튜브가 패션필름 의 전파속도를 향상시키는데 일조하였기 때문이다. 이 처럼 현대사회는 이미지의 공유뿐만 아니라 동영상 공유의 시대로 넘어가고 있는 과도기라 할 수 있다. 기존에 내용을 중심으로 포스팅하는 블로깅(blogging) 의 행태가 영상 위주의 블로깅 형태로 발전함에 따 라 블로깅(vlogging)이라는 신조어가 파생되었고 동 영상을 공유할 수 있는 SNS 및 모바일 관련 어플리 케이션도 등장하고 있다. 이와 같은 사회적 변화는 이미지가 더욱 중요한 요소로 여겨지는 사회 세태를 반영한 결과라고 할 수 있다. 이와 더불어 패션필름 도 새로움을 추구하는 과정에서 기술과의 접목이 활 발하게 진행되어 $\mathrm{QR}$ 코드를 활용한 모바일 전용 패 션필름이 제작되거나 모바일 기기를 통해 패션필름 을 배포함으로써 브랜드와 소비자 간의 전통적인 소 통 방식이 대체될 수 있을 것이다. 이처럼 현대사회 의 쌍방향 커뮤니케이션 도구로서의 패션필름은 다 양한 미디어를 기반으로 브랜드와 소비자 사이의 교 감을 이끌어내는 역할을 지속적으로 수행할 수 있을 것이다.

인터넷과 모바일이라는 장치를 기반으로 전파될 수 있는 패션필름의 무한한 가능성을 감안한다면 앞 으로 패션필름에 관한 심도 있는 연구가 이루어져야 할 것이다. 본 연구에서는 도식적인 분류 방법을 통 해 패션필름을 유형화하고자 하였으나 본 연구의 분 류 기준에 포함되지 않는 형태의 패션필름이 존재하 고 있는 것이 사실이다. 이에 후속연구에서는 다양한
형태의 패션필름을 아우를 수 있는 세분화된 분류 기준이 마련되어야 할 것이며 다양한 관점에서 패션 필름에 접근하는 새로운 연구가 수행되어야 할 것이 다. 이와 더불어 패션필름이 소비자에게 빠르고 효과 적으로 전달될 수 있도록 하는 패션필름 플랫폼에 관한 연구도 진행되어야 할 것이다.

\section{References}

Alexander McQueen F/W (2006, September 24). Retriev ed from https://www.youtube.com/watch?v $=\mathrm{kWo}$ QqrRk0ss

Andrea, K. (2013). The Devil of Fashion: Wome, Fashion, and the Nation in Early-Twentieth-Century German and Swedish Cultural magazines. In Hancock, J. H., Johnson-Woods, Toni., \& Karaminas, V (Eds.), Fashion in Popular Culture: Literature, Media and Contemporary Studies. Intellect.

Bartlett, D., Cole, S., \& Rocamora, A. (2014). Fashion Media Past and Present. Bloomsbury.

Cartier The Proposal (2015, February 2). Retrieved from https://www.youtube.com/watch?v=n9AZUAYLF $\mathrm{Kg}$

Cho, Y. K. (2009), A study on the classification system of the motion in motion graphics, Korea Digital Design Council, 9(1), 121-122.

Cheon, J. E. (2015). Immersive Media Contents Development through the Convergence of Video Technology of Next Generation: Focused on Flattype 3D Hologram, Workshop on Video Processing and Understanding, 27, 1.

Do, K. E. (2014), A study on pop art kidult culture. Journal of Digital Convergence, 12(2), p. 484. doi: 10.14400/JDC.2014.12.2.483

Diesel 'Liquid Space' Holographic Fashion Show (2007, June 26). Retrieved from https://www.youtube.co $\mathrm{m} /$ watch? $\mathrm{v}=$ CCcTRjxP-Fc

Gareth Pugh A/W (2009, March 4). Retrieved from http: //showstudio.com/project/gareth_pugh_a_w__og/fa shion_film

Hansen, M. (1994). Babel and Babylon: Spectatorship in American Silent Cinema. Harvard University Press.

Hermès Roulotter - Hand rolling (2011, January 21). Ret rieved from https://www.youtube.com/watch? $\mathrm{v}=\mathrm{b}$ cVQFmBCCA0

Hermès Super H (2014, November 24). Retrieved from $h$ ttps://www.youtube.com/watch? $\mathrm{v}=\mathrm{XGdmdGYpG0I}$

Hong, Y. J. \& Kim, Y. I. (2013). Study on the Digital Storytelling Types and Characteristics of Fashion Designer Brands. The Korean Society of Costume, 63(8), 52. 
Hwa, Y. (2013). A study of the emotional expression of motion graphic (Doctoral Dessertation, Yeungnam University, Republic of Korea). Retrieved from http://www.riss.kr/link?id = T13481812

Hwang, S. W. (2014). Special Fashion Film of Park Chan Wook: Collaboration with Ermenezildo Zegna, 10asi a, http://tenasia.hankyung.com/archives/304664

Jang, R. Y. \& Yang, S. H. (2010). 21 Century Video Image Fashion Communication: Focusing on Prada Fashion Animation. The Research Journal of the Costume Culture, 18(6), 1318-1330.

Jang, T. S. (2006). A Study on the basic elements of the motion graphic in the digital media world. The HCI Society of Korea, Conference 2, 1773-1774.

Jensen, R. (2005). Dream Society. (J. H. Seo, Trans.). Readlead. (Original work published 2001)

Jeon, P. G. (1994). Video Documentary Theory: Theory and Practice, Nanam.

Jung, J. S. \& Kim, J. H. (2013). A Study of Alexander McQueen's Fashion Performance. The Korean Society Of Knit Design, 11(3), 89

Kim, S. H., Shin, D. H., \& Kim, E. S. (2014). Integral Imaging and Digital Holography Techniques for Three-dimensional Sensing. Imaging and Display. Korean Journal of Optics and Photonics, 25(4), 178 참고. doi:10.3807/KJOP.2014.25.4.169

Kim, S. J. \& Ha, J. S. (2015). The study on metareality expressed in digital fashion film. The $\mathrm{cos}^{-}$ tume culture association, 23(4), 554-568. doi:10.7741/ ricc.2015.23.4.554

Kim, S. M. (2001). Introduction to the Development of Film Theory. Cineforum, 4, 11

Kim, S. Y. (2013). Aesthetic Characteristics Reflected in Gareth Pugh's Fashion Films. Journal of the Korean Society of Costume, 63(1), 1-15. doi:10. 7233/jksc.2013.63.1.001

Kim, S. Y. (2014a). A Study on the Utilization of Fashion Animation in the 21st Fashion Brand. The Korean Society of Design Culture, 20(2), 73-86.

Kim. S. Y. (2014b). Case and Value on the Prada's Fashion Communications Through Art Marketing. The Research Journal of the Costume Culture. 22(2), 258-272. doi:10.7741/rjcc.2014.22.2.258

Kim, J. T. (1999). Overcoming Lasswell and McLuhan From Effect - Media Paradigm to Symbolic Exchange Paradigm. Korean Society for Journalism and Communication Studies, 43(5), 113-154.

Kim, J. Y. (2013). Characteristics of Nick Knight's Works as a Fashion Visual Maker. Journal of the Korean Society of Costume, 63(4), 101-117. doi: 10.7233/jksc.2013.63.4.101

Kim, W. H. \& Shim, S. W. (2009), A Categorization of Brand Character in TV Commercials-focus on Narrative and Personification. Korea communication association, $17(3), 14$
Kwon, S. C. (2011). Digital hologram making system using the depth information of an image (Doctoral disseration, KwangWoon Unversity, Republic of Ko rea). Retrieved from http://www.riss.kr/link?id = T 12958423

Lee, E. A. (2008). A study on the changes in the communication between viewers and digital art as experience. Journal of Digital Design, 6(2), 168.

Lee, J. Y. \& Kwon, J. S. (2015). Image annotation system for mobile augmented reality environment. Journal of Digital Contents Society, 16(3), 437. doi:10.9728/dcs.2015.16.3.437

Lee, K. S. (2012). The Digital Generation and a Cultural Politics Using Social Media. Journal of Korean Social Trend and Perspective, 84, 106.

Lee, S. H. (2006). A Study on the Interactivity of Media Technology. Korea Design Knowledge Journal, 2, 373.

Lee, S. Y. (2013). A study of 3D animation using projection mapping in the space on the utilization. The Korean Society of Cartoon \& Animation Studies, 33, 452. doi:10.7230/KOSCAS.2013.33.449

Lev, M. (2004). (The)Language of new media. (J. S. Seo Trans.). Seoul, South Korea: Tree of Thinkig. (Original work published 2001)

Louis Vuitton F/W Accessories with Quentin Jones (201 3 , October 9). Retrieved from https://www.youtub e.com $/$ watch? $=$ vsnIa8e J3wc

Louis Vuitton Superflat First Love (2009, April 27). Ret rieved from $h$ ttps://www.youtube.com/watch?v $=\mathrm{X}$ JLc8bddXrU\& index $=2 \&$ list $=$ PLJtWRMDqy9URB5 XU9R8tRkSAD9Wtjbr40

Mijovic, N. (2013). Narrative Form and the Rhetoric of Fashion in the Promotional Fashion Film. Film, Fashion and Consumption, 2(2), 182-183.

MiuMiu Muta (2011. September 30). Retrieved from htt $\mathrm{p}: / /$ www.miumiu.com/en/women_tales/2/film?cc $=\mathrm{AP}$

Nike Jordan Melo M8 Water Projection (2011, October 2 4). Retrieved from https://www.youtube.com/watc $\mathrm{h} ? \mathrm{v}=\mathrm{naJVL} 5 \mathrm{GFSCQ}$

No, S. Y. (2014). Digital Art. Jamo.

Paik, J. H. \& Bae, S. J. (2012). A Study on the Application of Art and Culture in Luxury Fashion Brand: Focused on PRADA's Case. Journal of Fashion Business, 16(5), 146-163.

Paik, R, R (2011) 'Liveness' of Performance in the Age of Media Technology. International Association for Humanistic Studies in Language, 13(2), 289317.

Paik, W. I. (2010). Knowledge, Media and Information in the Age of Digital Reproduction. Korean $\mathrm{As}^{-}$ sociation for Communication and Information Studies, 49, 15

Park, K. D., Kim, T. H., \& Jung. J. H. (2013). A study 
on the transparent screen projection mapping using depaysement. The Journal of Digital Policy \& Management, 11(8). 333.

Paul Smith Underwear A/W (2013, October 1). Retrieve d from https://www.youtube.com/watch?v $=8 \mathrm{q} 909$ r4GTNA

Ralph Lauren The Official Ralph Lauren 4D Experience - New York (2010, November 12). Retrieved from https://www.youtube.com/watch?v=c3n8j2uWA8o

Ryu, C. K., Han, H. W., Seo, S. E., An, J. K., \& Lee, D. E. (2015). Understanding of Transmedia Storytelling. Ewha Womans Unversity Press.

Seo, J. W. \& Kim, J. K. (2014). Convergence of Thinking and Brand Associationg: Focused on art collaboration with Louis Vuitton. Journal of Digital Design, 14(3), 518-519.

Sheridan, J. (2013). Fashion, Media, Promotion: The New Black Magic. Wiley-blacwell.

Shin, C. W. (2004). An Observation of the Visual Language and the Visual Technology according to the Media Technology. Journal of Korean Society of Design Science, 17(2), 15-22.

Shin, D. H. (2015. December 15). Come on. Would you buy my 'taste'?, Chosun.com. Retrieved from http: //news.chosun.com/site/data/html_dir/2015/12/15/ 2015121500192.html

Stam, R. (2012). Film Theory. (B. C. Kim, Trans.) Seoul, South Korea: K-books. (Original work published 2000)

Stella, B. (1995). Film and Fashion. Sight and Sound, $5(6), 10-15$.

Stella, B. (2013). Fashion Cultures Revisited: Theories, explorations and analysis. Routledge.

Uhlirova, M. (2013). 100years of the Fashion Film: Frameworks and Histories. Fashion Theory, 17(2), 137-158.

Yoo, J. Y. (2004). A Study on Space Expression According to the Production Characteristics of Reflex Media. Korean Institute of Interior Design. 13(6), 180.

Yoon, T. J., Lee, C. H., \& Lee, H. K. (2003). Changes of conception of time/space and of the public/private life with the introduction of new media technology. Korean Association for Broadcasting \& Telecommunication Studies, 57, 179-207. 